\title{
Climate Change Governance: Bangladesh Perspective
}

\author{
Mujibur Rahamn Khan* \\ *Professor of Agronomy under College of Agricultural Sciences
}

Received: October 01, 2016; Accepted: January 26, 2017; Published: March 14, 2017

*Corresponding author: Mujibur Rahman Khan, Professor, International University of Business Agriculture and Technology, Uttara, Sector 10, Dhaka, Bangladesh; E-mail: drmrkhan@iubat.edu

\begin{abstract}
This paper provides a synthesis of works on relationship between governance and integrity in climate regime and develops recommendations for the policy planners to address the issues in climate regime with special emphasis on the developing nations such as Bangladesh which are more vulnerable to the climate change. The methodology involves analyzing historical data, review of scientific findings and grey literatures in climate change regime including author's own thesis on crop weather modeling.

There is no denying the fact that good governance is closely associated with integrating climate change for sustainable development. The Climate Change Governance (CCG) programmer started at International Centre for Climate Change and Development (ICCCAD) in 2013 with main objectives on financing on global and national context. The programmer includes governance challenges within climate change regimes by engaging multiple stakeholders from both government and non-government institutions. The programmer started from Bangladesh and has since then expanded to include broader governance considerations. The integration of academics, government officials, environmental scientists and agronomists as well as grass roots level is considered as crucial for successful implementation of climate change mitigation process. The successful completion of COP21 through the historical Paris Agreement has opened a new vista in climate change regime where all stakeholders share Nationally Developed Contributions (NDCs). Leaders of 175 countries signed on the Paris Agreement on the Earth Day (22 April 2016) in the UN Head HQs. This signifies the seriousness of the world leaders in implementing the Agreement. The paper extensively draws on issues related to climate change in Bangladesh, adaptation and mitigation challenges and post COP 21 updates in relation to Bangladesh as the most vulnerable country. The benefits arising from the qualities and mechanisms of governance (accountability, participation, etc) are enhanced when we ensure the institution's activities and goals are integrated into its surrounding environment. The recent award of "Champion of the Earth" conferred upon Prime Minister of Bangladesh by the United Nations Environment Programme (UNEP) is a recognition of Bangladesh, in being a pioneer among nations in tackling climate change. Bangladesh leads the world in the number of Solar Home Systems (SHS) installed (now well over three million) through a very successful model of public-private partnership of the Infrastructure Development Company (IDCOL) and its franchise model of delivering SHS to millions of customers around the country.
\end{abstract}

Methodology. The methods of research employed in developing this paper includes desk study of relevant literature, articles, essays, conference proceedings and the like materials available in published form in books, peer reviewed materials, journals, magazines, newspapers, printing and electronic media and blogs besides synthesis from own research works.

Keywords: CCG; CCS; CGFC; CCS (Carbon capture and storage); COP 21; CSO (Civil society organizations); global warming; ICCCAD; IPCC; NDCs; NGOs; UNCC;

\section{Background}

Carbon dioxide $\left(\mathrm{CO}_{2}\right)$ is an important trace gas in Earth's atmosphere currently constituting about 0.04 percent (400 parts per million) of the atmosphere [1,2]. Despite its relatively small concentration, $\mathrm{CO}_{2}$ is a potent greenhouse and plays a vital role in regulating Earth's surface temperature through radioactive forcing and the greenhouse effect [3] Carbon dioxide is essential to life on Earth and is an integral part of the carbon cycle, a biogeochemical cycle. The present biosphere of Earth could not exist without atmospheric $\mathrm{CO}_{2}$. Carbon dioxide is well mixed in the Earth's atmosphere and reconstructions show that concentrations of $\mathrm{CO}_{2}$ in the atmosphere have varied significantly over the last millions of years ( from as high as 7,000 ppm in 500 million years ago to $180 \mathrm{ppm}$ last two million years ago). The current episode of global warming has been attributed primarily to increasing industrial $\mathrm{CO}_{2}$ emissions into Earth's atmosphere. The global annual mean concentration of $\mathrm{CO}_{2}$ in the atmosphere has increased markedly since the industrial Revolution, from $280 \mathrm{ppm}$ to $400 \mathrm{ppm}$ as of 2015 . The present concentration is the highest in the past 800,000 years [4] and likely the highest in the past 20 million years [5]. The increase has been caused by anthropogenic sources, particularly the burning of fossil fuels and deforestation [6]. At the backdrop of the present situation the Workshop on 'Global Carbon Governance: Towards a Global Carbon Integrity System and Climate Justice?' seems to be a timely step forward.

\section{Impact of Climate Change in Bangladesh}

Bangladesh situated between the latitudes of 20050 ' $\mathrm{N}$ and $26020^{\prime} \mathrm{N}$ and longitudes of $88050^{\prime} \mathrm{E}$ and $92050^{\prime} \mathrm{E}$ receives over $3000 \mathrm{~mm}$ of rainfall annually. The highest temperature during 
summer does not exceed 430C and the lowest temperature during winter does not go below 40C with a maximum of 290C. The mean maximum temperature varies from 300 to $320 \mathrm{C}$. Bangladesh is basically an agrarian economy and rice is the staple food crop of her nearly 160 million people living in a small area of roughly $144,000 \mathrm{sq} \mathrm{km}$. Located at the bottom of the mighty GBM (The Ganges, the Brahmaputra and the Meghna), Bangladesh is watered by a total of 57 trans-boundary rivers coming down to it. Out of these 54 originates in India and three in Myanmar. Virtually, Bangladesh has no control over the water flow and the volume. Floods, excess rainfall, tropical cyclones and drought are some of the common natural disaster the people of Bangladesh face as annual events. On the top of it, high density of population (estimated 1000 people per $\mathrm{Km}^{2}$ ) and low purchasing power parity (1.25 \$ a day) has put Bangladesh as one of the most vulnerable countries to climate change. It ranked first on German Watch's Global Climate Risk Index of 2011[7].

Khan 1983 [8] conducted a crop-weather modeling study and derived statistical models of crop yields and weather elements such as monthly rainfall, maximum, minimum and average temperature and solar radiation. He observed more vulnerability of modern rice varieties to the extreme weather conditions as compared to local rice varieties. He recommended for development of genetically fit rice varieties for adaptation to extreme climate situations such as drought and floods. Since her independence ,Bangladesh survived the rigorous test of Nature by facing at least six main cyclones which are : (1) Bhola Cyclone (1970; death casualty 500,000 people); (2) Bangladesh cyclone (1991; death casualty 138,000 people); (3) Sidr ( 2007; death casualty 4036 people); (4) Nargis (2008; death casualty 126 people in BD); (5) Aila ( 2009; death casualty 26 people in Bangladesh and (6) Mohasen (2013; death casualty 17 people in $\mathrm{BD}$ ). The gradual decrease in death tools due to natural disaster, like cyclone in Bangladesh is a vivid example of good governance and community participation in climate change regime.

Rahman [9] observed that establishing an integrated Coastal Zone Management (CZM) policy with adequate attention to natural systems and scientific connotations of these systems could help in mitigation of impacts of natural disasters in the coastal zones of Bangladesh. As to policy implications the Workshop observed that contextual information on climate change regime is rather scanty in the Asian LDCs and Small Island Developing States (SIDS). However, coping with climate extreme may be facilitated through vulnerability categorization for priority, development of drought resistant crops, saline resistant crops and flood resistant crops and trees, agronomic manipulations on cultural practices and crop diversification, creation of deep water reservoir, integration of traditional wisdom and community development on reducing flood risk and loss of lives, construction of multipurpose flood shelters, early warning for disasters, and bio-fortification of cereals for managing droughts. Hotspots of climate change vulnerability from the point of both biophysical and socio-economic vulnerability are: the central and western coastal area, the north -western high lands and along the main rivers, as mentioned above.

\section{Adaptation to Climate Change in Bangladesh}

Lessons learned from Adaptation to climate change in Bangladesh [10]. Since the early nineties, a number of studies have been carried out which have built a body of knowledge and information about the likely adverse impacts of climate change to different sectors of the country's economy. The World Bank published the results of a study in 2000 as Bangladesh: Climate Change and Sustainable development (Report No. 21104-BD). The overall objective of the study was to mainstream climate change adaptation issues in the regular development strategies and operations in Bangladesh as an example for other countries of the world.

The study involved five key sectors of the economy, namely: Coastal resources, Freshwater resources, Agriculture, human health and ecosystems and Biodiversity. The most important impact on coastal resources were determined to be on drainage congestion, morphological processes and disaster mitigation. The most important impact on fresh water flows were determined to be on reduced low flows and drainage congestion.

The most important impact on the agriculture sector were determined to be on drought impacts, flood impacts and Stalinization impact on human health were determined to be on water borne diseases and vector borne disease. The most important impact on ecosystems and biodiversity were determined to be on the Sundarbans mangrove ecosystem (the largest mangrove ecosystem in the world), other coastal ecosystems and wetland .The evidence from Stern Review [11] shows that the developing countries cause a little damage to climate but they are currently experiencing or will experience more environmental hazards, because of their limited capacity for adaptation. With her current economic growth and social development, it would be extremely difficult for Bangladesh to cope with the climate change vulnerabilities. Affected people mostly use migration as an adaptation strategy. Bangladesh had experienced migration of 49 million displaced people in 2010 which is expected to rise to 63 million in 2015 and 78 million in 2020 due to climate change.

\section{Climate Change and Migration in Bangladesh: Golden Bengal to Land of Disasters}

Bangladesh is the most vulnerable country in the world because of frequent floods. The country becomes the third and the sixth most vulnerable country in terms of tsunami and cyclones. Drought will affect eight million people by 2050 . In future, the combined effect of high population growth and displaced population will make the country more vulnerable to social and economic underdevelopment. With increasing climate change vulnerabilities, people will consider taking an advantage of international migration if resources became exhausted. For resolving the problems of many more environmental migrants in 
upcoming years, this is high time to think about future floods of environmental migrants and the adaptation measure necessary for the survival of many.

The adaptation measures to cope with climate change involve the use of technology and its management: development, transfer, adaption, adoption and diffusion. Water and agriculture sector has been identified as the most vulnerable ones where immediate technological interventions have been emphasized. [12]

The technology options for water sector include the following:

-Rehabilitation of existing embankment/dykes and dredging

-Tidal barriers ( sluice gates)

-Tidal river management including computer simulation of tidal flow

- Comprehensive disaster management incorporating early warning systems and involving community

-Monitoring od sea level rise, tidal fluctuation, salinity intrusion, sedimentation and coastal erosion and

-Urban infrastructure development

On the other hand the technology options for agriculture sector include:

-Development of salinity-tolerant rice varieties

-Development of drought-tolerant rice varieties

-Development of short-maturing rice varieties

-Training on improved farming practices for crops, irrigation and water management, soil fertility management ( conservation and restoration of soil quality) etc

-Establishment of climate- smart Agriculture Technology Dissemination Center

-Establishment of special agricultural R\&D center

-Land Use Planning

\section{Climate Change Extremes}

Modeling results predict a significant upward trend in extreme events in Bangladesh with climate change [13]. Models point to the likelihood that environmental hazards will increase, causing destruction to life and property and increasing costs of adaptation. . The climate models depict the following vulnerability:

-Drought Vulnerability. Reduced precipitation and increased evapo-transpiration will lead to extreme drought in the 21st Century. The climate-induced drought conditions will jeopardize food security due to yield reduction of high yielding rice and wheat varieties. Integrated drought management policy may help ease the situation.
-Sea-level Rise (SLR). SLR is predicted to rise by perhaps one meter by the end of the 21st Century. A majority of low lying non-embanked coastal areas of Bangladesh may be completely inundated, which will increase the risks of coastal salinity and scarcity of fresh water. Integrated coastal zone management planning for infrastructure development and development of salt-tolerant crop varieties should receive high priority.

- Cyclone Extremes. Exposure to cyclone -induced storm surges is likely to increase significantly by the year 2050. By 2100 a higher frequency and greater severity of storm-induced coastal inundation s, higher ocean surface temperature and rising sea levels. Redesigning the disaster management plans will be necessary to address this issue.

\section{Climate Change Mitigation Challenges of Bangladesh}

Being a densely populated country with limited natural resources, Bangladesh is deadly suffering from the energy crisis since the past few decades. The geographical location of the country has even made it more vulnerable to the natural disasters. As a result, the country is experiencing the impact of current weather change and the economy is struggling to improve against the periodic occurrence of natural calamities such as cyclones, floods and drought. In spite of being in the row of least carbon producers, Bangladesh is one of the worst sufferers. Due to the limitation in fossil fuel reserve, the only way to minimizing the supply-demand gaps in the energy sector is switching towards the alternative renewable energy sources. The initiatives in sourcing out alternative energy sources with low carbon emission from both the government and the privet investor are still on the infancy stages. Local investor has started the initiations to switch towards renewable energy system. There have been some remarkable achievements as the rural people have started using these green energy systems. Governments have already taken necessary steps to energize the local economy through inspiring them by low interest loan schemes, and introducing the energy usage in the government owned offices. The renewable energy system is showing a lot of promise in Bangladesh, with the proper technical support and large production, Bangladesh will be one of the world leaders in adaption of renewable energy system. Renewable energy with low carbon emission is an opportunity for Bangladesh.

-Solar energy

-Wind energy

-Biomass

-Biogas

-Hydro power

\section{Solar Energy}

The unique geographical location (20043/ and 26038/N latitude) of Bangladesh is considered as the most favorable spot for consumption of solar energy (against the standard between 
150 and $35^{\circ}$ latitude North and South). Annual amount of radiation varies from 1840 to $1575 \mathrm{kWh} / \mathrm{m}^{2}$ which is technically feasible compared to the other areas in South East Asia. The total annual solar radiation in Bangladesh is equivalent to $1010 \times 1018$ J considering the average of $1900 \mathrm{kWh} / \mathrm{m}^{2}$. Present total yearly consumption of energy is about $700 \times 1018 \mathrm{~J}$. So the utilization of about 0.07 percent radiation will be able to meet the energy crisis of Bangladesh. At present energy utilization in Bangladesh is about $0.16 \mathrm{~W} / \mathrm{m}^{2}$ land area, where as the availability is above $208 \mathrm{~W} / \mathrm{m}^{2}$ [14].

\section{Wind Energy}

The potential wind energy is mainly limited to the coastal areas where the velocity of wind is considerably higher [15].

\section{Biomass}

Common biomass resources available in the country are: sugarcane baggage, rice husks, crop residues, waste wood, animal and municipal wastes etc. The sugarcane baggage produced form different sugar mills could be utilized in production of alternative energy. Total biomass fuel s of an estimate (2004) amount to 11.858 million tons of coal equivalent [16].

\section{Biogas}

Biogas mainly from animal and municipal wastes may be one of the promising renewable energy resources for Bangladesh. Bangladesh Council for Scientific and Industrial Research (BCSIR) has developed bio-gas plants suitable for the country. A good number of bio-gas plants have already been set up through the country. In another feasibility study it has been indicated that up to $800 \mathrm{MW}$ of electricity could be produced using organic city wastes and poultry litters [17].

About 80 percent of produced wastes is organic which have a high potential for biogas production. The amount is expected to rise up to 47,000 tons in 2025 [18].

\section{Hydro power}

The only hydro power station of the country, the Karnaphuli Hydro Power Station has a generating capacity of 230 MW. Microhydro and mini-hydro have limited potentials in Bangladesh, with exceptions of Chittagong and the Chittagong Hill tracts. The Sangu River Project and the Matmuhuri Development Projects have a potentail installed capacity of $140 \mathrm{MW}$ and $75 \mathrm{MW}$ respectively. There are seven small scale hydro power generation potential sites in khagrachari, Banderbans and Rangamati Districts [19]. Other renewable energy sources include bio-fuels, gasohol, geothermal, river current, wave and tidal energy. However, potentials of these sources are yet to be explored.

\section{Mitigations need adaptation: Tropical Forestry and Climate Change}

The relationship between tropical forests and global climate change has been largely focused on the mitigation, while much less information is available on how management activities may help forest ecosystems adapt to this change. Tropical forests and forest-dependent communities appear not to appreciate the risks posed by the climate change and for those who are aware of them; practical guidance on how to respond is largely non-existent. The extent to which forestry research and national policies will promote and adapt management practices in order to assist production forests adapt to climate change is currently uncrating. Mainstreaming adaptation into national development and planning programs may represent initial step towards the incorporation of climate change consideration into tropical forestry. SADMC [20] outlined the following steps to address forestry in climate change mitigation.

\section{Afforestation}

Imported species planted in Bangladesh have been found to be vulnerable to drought and food, reducing their life span significantly. Afforestation through plantation of homogeneous and area-wise appropriate species by the side of roads, canals can have may beneficial result. Among they are increasing local soil moisture and humidity, restoring a more balanced ecosystem, and increasing regional precipitation.

\section{Choice of Plant}

Indigenous plants have adapted to adverse situation created by flooding and water logging; however, plant varieties imported from other continents (e.g. Acacia mangium, Eucalyptus camaldulensis) are less effective. Due to lack of information, farmers often choose non-adaptive to environmental intersect dominate decisions on import of species in the private and public sector. Most of the indigenous varieties and being eliminated from species lists used by the Department of Forestry. This need to be reversed through policy intervention and scientific investigation of habits and habitats of plant in flood-prone condition.

\section{Plantation Site}

Flood damage can be reduced by choosing plants according to the adaption requirement of the species, corresponding to specific climate and physiographic condition. Although Bangladesh is flood-prone and subject to water logging, this aspect is largely ignored in growing site-specific plants, particularly in organized plantations of the Department of Forest. Development of a policy framework on site-specificity of plants has the potential to improve the situation.

\section{Mitigation Challenges}

Given the opportunities in the renewable energy sector in Bangladesh, there have been a plenty of obstacles that need to be overcome. Lack of technical information on the feasibility study discourages the investors to go for a bigger plan of action. Bangladesh currently do not have any central database for the primary survey report. Currently GOB is focusing on quick rental power generation which can only be considered as a short term solution for the projected energy crisis. The Environmental Laws and Acts of the country are not up to date to be considered to fulfill the current environmental goals. 


\section{COP 21: What's next for Bangladesh}

Parties to the UN Framework Convention on Climate Change (UNFCCC) reached a landmark agreement on December 12, 2015 in Paris, charting a fundamentally new course in the two-decade -old global climate effort. Culminating a four-year negotiating round, the new treaty ends the strict differentiation between developed and developing countries that characterized earlier efforts, replacing it with a common framework that commits all countries to put forward their best efforts and to strengthen them in the years ahead. This includes, for the first time, requirements that all parties report regularly on their emissions and implementation efforts, and undergo international review.

Outcomes of the UN Climate Change Conference in Paris. 21st Session of the Conference of the Parties to the United Nations Framework Convention on Climate Change (COP 21). (November 30-December 12, 2015).Together, the Paris Agreement and the accompanying COP decisions are as follows:

-Reaffirm the goal of limiting global temperature increase well below 2 degrees Celsius, while urging efforts to limit the increase to 1.5 degrees;

-Establish binding commitments by all parties to make" nationally determined contributions " (NDCs), and to pursue domestic measures aimed aat achieving them;

- Commit all countries to report regularly on their emissions and "progress made in implementing and achieving" their NDCs , and to undergo international review;

- Commit all counties to submit new NDCs every five years, with the clear expectations that they will "represent a progress" beyond previous ones;

- Reaffirm the binding obligations of developed countries under the UNFCCC to support the efforts of developing countries, while for the first time encouraging voluntary contributions by developing countries too;

-Extend current goal of mobilizing \$100 billion a year in support by 2020 through 2015 , with a new, higher goal to be set for the period after 2025 ;

-Extend a mechanism to address "loss and damage " resulting from climate change, which explicitly will not "involve or provide a basis for any liability or compensation;

-Require parties engaging in international emissions trading to avoid "double counting" and

- Call for a new mechanism similar to the Clean Development Mechanism under the Kyoto Protocol, enabling emission reduction in one country to be counted towards another country's NDC.

With the endorsement of 196 countries, the Paris Agreement becomes the first universal climate deal and a crucial instrument to limit and mitigate the negative impacts of climate change. Countries and communities all over the world feel the challenges of the climate change. The most vulnerable ones are already hit by the effects of climate change. In Bangladesh the effect is obvious in many forms as already discussed. Loss of lives, colossal damage of assets, undermining livelihood, displacing people from their lands and migrations are some vivid examples of climate shocks and stresses. The Agreement reached in Paris marks turning point on how the world will address climate change. The Paris Agreement sends a message to the world that countries are serious about addressing climate change. Where the Kyoto Protocol only required certain countries to cut emissions, the Paris Agreement requires all countries to take actions, while recognizing their differing situations and circumstances. Responsible for taking actions on both mitigation and adaptation countries have officially submitted their own nationally determined climate action plans, including cutting emissions. They now have an obligation to implement these plans; and if they do, it will bend the curve downwards in the projected global temperature rise. The individual contributions of states all over the world will be crucial to the highly exposed countries like Bangladesh, where climate change effects, like rising sea levels, severe flooding, prolonged drought and changing cyclone patterns are already felt.

Bangladesh has already intensified its efforts to integrate the Sustainable Development Goals (SDG) into its Seventh Five Year Plan. Goal 13 of the SDG requires to take urgent action to combat climate change and its impact-as a key national concern. The Paris Agreement calls for the support of the UN agencies to countries in implementation. In line with this, the UN will continue to support the Government of Bangladesh with high quality policy advice and program support. The Paris Agreement confirms the necessity for Bangladesh to take actions and adapt to keep lives and livelihood safe in a changing climate and to adopt a lowemission economy to continue growing as a prosperous country. Bangladesh is already mobilizing access to funds from the Green Climate Fund to build the resilience of communities along the coasts and in other climatic hotspots.

Now it is the for markets to invest in the low-emission economy and to move away from fossil fuel in order to minimize the loss and damage from climate change.

The Paris Agreement represents a unique opportunity for Bangladesh and the rest of the world to move towards a global transformation that will help safeguard our planet for generations to come [21]

In a post COP 21 Update seminar Tim Cadman put emphasis on adaptation and mitigation challenges to be faced by the participating countries. The governance and integrity issues with accountability and transparency in handling the climate change funds [22].

\section{Good Governance Essential for Climate Regime Policies and Integrity Governance}

\section{Governance}

The idea of 'governance' employed centers around that which 
the Workshop Concept-Paper refers to as C: 'Thick-ish: objective list'. That is, governance refers to key structural and process values, such as transparency, accountability, participation and deliberation, as well as attention to efficacy and problem-solving. (Similar to the Cadman Framework) (Hugh Breakey) [23]

\section{Integrity}

The notion of 'integrity' employed focuses on the integration of the institution (or institutional task) into its surrounding social, political and organizational environment. This is what the Concept Paper for the previous Workshop (Brisbane, Nov 2014) termed 'context integrity' [24]

Integrating climate change into development decision making Central to the notion of sustainable development, first formulated by the Brundtland Commission more than twenty years ago, is the idea that environment and development decision making should be linked [25]

Climate change policies can only be successful if they are formulated in relation to economic and social realities and goals. In particular, climate change policies need to be integrated into the development trajectories of a) key socio-economic sectors (energy, industry, transport, and so on); and b) key regions (cities, provinces, and so on) (Lafferty 2004)[26]. Integration implies an attempt to find synergies among different types of goals [27]. For example, some mitigation approaches can provide positive economic benefits (removing subsidies that encourage energy use saves money as well as lowering emissions) and/or health benefits (fuel switching from coal to gas reduces urban air pollution and associated respiratory disease; improvements in rural cook stoves can improve indoor air quality). A shift away from deep tillage agriculture may provide diverse benefits including reduced soil erosion, higher carbon dioxide retention in the soil, reduced fertilizer inputs, and so on. The need for good governance has been emphasized in numerous workshops, seminars and conferences held on the subject for the past decades. Remarks pertaining to this have included highlighting the need for increased capacity in fiscal management. At the same time, delegates have recognized that maintaining good governance does not simply include budgetary planning; participation, particularly by civil society, is also essential.

While academics, government officials, and scientists have been recognized as crucial to the climate change mitigation process, there is similarly a need for grassroots approaches to adaptation measures .Indeed, it is at the local level where governments can be held accountable for their policies. Good governance measures can ensure that all sectors remain transparent, participatory, and accountable. Since the Rio 'Earth' Summit of 1992, sustainable development has become the major policy framework through which the international community deals with pressing environmental issues such as deforestation. Implicit in this approach is the belief that the market provides the best mechanism to bring government, business and society together, and a whole plethora of market-driven schemes have been developed in response.
"Yet how legitimate are these institutions, and where is their democratic accountability?" Questioned Tim Cadman ${ }^{[28]}$ in his Paper on Contemporary Governance Theory (From Wikipedia, the free encyclopedia).Contemporary Governance Theory (19902010) identified in comparative politics, public administration, international relations and political economy (Tim Cadman) ${ }^{\text {[ibid] }}$ Governance itself is also more understood in terms of how it is manifested not merely at the national and international level, but at all spatial scales, demonstrated by the interactions between decentralized networks comprising multi-stakeholders active at all levels, from the local to the global, and vice versa. Global environmental governance exemplifies this development strongly. In the light of research experience, this re-emerged a decade later the 2000s in terms of 'governance as structure', concerning the models of interaction utilized by various institutions, and 'governance as process', linked to the older theoretical idea of governance as steering or coordinating, but recognizing the newer preference for 'co' arrangements, referred to above. In view of such these conceptual developments, there have been calls for researchers to make governance more effective by improving institutional design. In response more recent theorists in the have argued that contemporary governance is better interpreted as being based around the institutional relationship between participation as structure and deliberation as process. In this conception, there is a functional significance underlying the nature of participation and deliberation in different institutions; the type of institution is less important than how participation and deliberation occurs within it; it is these interactions, which determine the effectiveness, or quality, of its governance, and ultimately the degree of institutional legitimacy (Tim Cadman) [29].

\section{Climate Change Governance (CCG)}

The CCG programmer [30] started at ICCCAD in 2013 and has been one of the prominent initiatives within the organization. The primary concentration of CCG is on finance and policy in both global and national contexts.

The programmer was designed to address the governance challenges within climate change programmers and policies by engaging with multiple stakeholders from both government and non-government institutions with specific objectives to ensure governance issues, ensure use of funds for most vulnerable communities and through the expertise of ICCCAD and its partners, ensure all stakeholders are exposed to relevant and grounded knowledge that can be shared and transmitted around the world for the benefit of other Least Developed Countries (LDC), and their governments, donors and international NGOs ${ }^{[31]}$. The programmer started its journey by looking at mechanisms for financing local adaptation in Bangladesh and has since then expanded. One of the first projects under the CCG project looked to strengthen partnerships for capacity building and finance for local level adaptation. Later on it expanded its working area to include broader governance considerations. The historical background for the last fifty years, there has been an increasing 
awareness that human use of the earth is approaching a range of environmental and resource limits and that this trend, rather than diminishing, is escalating at an alarming rate. During the 1970s, while the developed world was considering the effects of global population explosion, pollution and consumerism, the developing countries, faced with continued poverty and deprivation, regarded development as essential - to provide the necessities of food, clean water and shelter. There was a UN conference on the environment in 1972 and in 1980 the World Conservation Strategy document was published and followed in 1982 with the World Charter for Nature that drew attention to the decline of the world's eco-systems. Faced with the differing priorities of the developed and developing world, a UN Commission worked for two years to try resolving the apparent conflict between the environment and development. This Commission, now known as the Brundtland one, concluded the development was acceptable but had to be "sustainable". It had to be directed to meeting the needs of the poor in a way that no longer caused environmental problems but helped to solve them. In the words of the Commission: Sustainable development is development that meets the needs of the present without compromising the ability of future generations to meet their needs"(Nicholas Genis,2008) [32].

\section{Policy Research Working Paper 4941 Climate Change Governance}

Policy Research Working Paper 4941 [33]. Climate change governance poses difficult challenges for contemporary political/ administrative systems. These systems evolved to handle other sorts of problems and must now be adapted to handle emerging issues of climate change mitigation and adaptation.

Thispaper exploresthechallenge ofclimatechangegovernance, examining in particular the role national governments can play in putting in place institutions, policies, plans and measures to promote mitigation of, and adaptation to, human induced climate change. Specific instruments and approaches impose particular demands on public bodies. Carbon taxes, for example, require an effective system of national taxation, while cap and trade systems require appropriate mechanisms of regulatory oversight.

Deforestation currently accounts for 25-30 percent of human generated carbon dioxide emissions, with most occurring in tropical and temperate areas of Africa, Asia and Latin America. Reducing this rate, and developing ways to manage forests more sustainably is one way in which middle and low income countries can make a contribution to mitigation in the coming decade. There is substantial evidence that much of the deforestation generates little long term economic value or contribution to sustainable livelihoods. So improvement of governance in the forest sector, and the integration of climate concerns into this governance, can bring economic and social as well as climate benefits. Tackling this problem will require efforts of low and middle income supplier countries and large timber consumers, as well as funding from higher income states. Brazil provides an example of a country whose government has recently reaffirmed its commitment to strengthen action in this area.

\section{Key Dimensions of Climate Regime Governance and Integrity}

Good governance on climate change requires a redefinition of national interests in light of climate change risks. This necessarily entails an effort to understand the potential implications of climate change, and the costs and benefits of possible mitigation and adaptation responses. On the basis of such effort, all governments should be able to formulate an overall perspective on the significance of human induced climate change on long term national welfare in the light of COP 21: the Paris Agreement.

These may take many forms including independent agencies, publicly funded trusts, joint public/private/not for profit partnerships, and so on.

Areas for the attention of such bodies focused on the low carbon future include: (a) research on the transition to a low carbon economy on all sectors (b) education of the public on the science of climate change (c) stimulation of public debate and controversy around options for a low carbon future (d) critical assessment of national and international policy measures (e) support for the development of low carbon technologies that are not yet ready for commercialization (f)encouragement for community engagement with climate change $(\mathrm{g})$ training for professions in low carbon technologies and providing help to public and private bodies seeking to reduce their carbon footprint and (h) assistance for those seeking to establish new businesses in the low carbon sector.

\section{Conclusion and Recommendations}

Bangladesh is recognized worldwide as one of the country's most valuable to the impact of global warming and climate change. This is due to its unique geographic location, dominance of floodplains, and low elevation from the sea, high population density, high levels of poverty and overwhelming dependence on nature, its resource and service. The country has a history of extreme climatic events claiming millions of lives and destroying past development gains. The people and social system have knowledge and experience of coping with their effects to some degree and extent. Variability in rainfall pattern, combined with increased snow melt from the Himalayas, and temperature extremes are resulting in crop damage and failure, preventing farmers and those dependent from meaningful earning opportunities. In a changing climate the pattern of impacts are eroding our assets, investment and future. This stands for families, communities and the state. Global warming and climate change threatens settlements and the number of people displaced from their land due to riverbank erosion, permanent inundation and sea level rise is increasing rapidly every year. Resource and efforts of government and people are quickly drained addressing the impact of one event when another hazard strikes. 
The historic COP 21: Paris Agreement has made climate change regime more universal than ever before. Bangladesh is prepared to accept the adaptation and mitigation challenges in response to the NDCs. However, as the most vulnerable nation to climate change, Bangladesh deserves world attention for implementing the gigantic task. Climate regime governance requires both the establishment of specific institutions, groups and policies and the integration of climate change into the normal practice of government. A central dimension of climate change governance involves finding approaches to activate dynamic forces in society to engage with the climate challenge. Important approaches to this task include sending consistent economic signals that encourage some behaviors and discourage others throughout society - for example, encouraging energy efficiency and discouraging the use of energy produced from high carbon emission sources; developing public education about climate change mitigation and adaptation. This includes changes to the curriculum of schools, colleges and universities. The media provide a critical link to the public, and activities can be organized to raise the awareness of journalists. Professional organizations (agriculturists, doctors, scientists, nurses, architects, engineers, public servants, teachers, farmers, and so on), business associations and trade unions also have an important educational potential. Cities and local governments can play the key roles in making mitigation and adaptation activities concrete for common citizens. The development of neighborhood based activities can activate a great dynamic potential for change. Encouraging participation of stakeholders from each walk of life in key socioeconomic sectors will help climate change regime in positive direction. Climate change governance involves complex and contested decisions and difficult policy choices. These decisions affect long term societal welfare and the distribution of costs and benefits. It is only right that citizens be involved in these decisions. In other words, governance works better at achieving results when the institution enjoys a high level of integration with its surrounding socio-politico-economic context. This means that working to create cultural ownership, improvements in education and training, and raising awareness about values and co-benefits, are all important 'integrity' tasks that improve what 'governance' has to offer.

\section{References}

1. The Guardian. Global carbon dioxide levels break $400 \mathrm{ppm}$ milestone 2015.

2. National Oceanic and Atmospheric Administration (NOAA). ESRL Global Monitoring Division - Global Greenhouse Gas Reference Network. 2015.

3. Petty GW. A First Course in Atmospheric Radiation. Sundog Publishing. 2004:229-251.

4. Amos Jonathan. Deep ice tells long climate story. BBC News. 2006.

5. Climate Change: The Scientific Basis. 2001.

6. Etheridge DM, Steele LP, Langenfelds RL, Francey RJ, Barnola JM, Morgan VI. Natural and anthropogenic changes in atmospheric $\mathrm{CO} 2$ over the last 1000 years from air in Antarctic ice and firn. Journal of Geophysical Research. 1996:101(D2):4115-4128.
7. Sven Harmeling. German Watch's Global Climate Risk Index of 2ISBN 978-3-939846-74-1.

8. Khan MR. Modeling Agro-climatic determinants for Rice-based cropping patterns in Bangladesh. Unpublished Doctoral Dissertation. University of the Philippines at Los Banos (UPLB). 1983.

9. Rahman. Policy Brief. Sustainable development in Bangladesh: Facing Global Environmental Issues. SADMC. IUBAT University.

10. Saleemul Huq. Climate Change Discussion Paper. Environment Department. The World Bank. 2002.

11. Stern. STERN REVIEW: The Economics of Climate Change. 2007.

12.GOB. Technology Need Assessment and Technology Action Plan for Climate Change Adaptation. 2012.

13.SADMC. Policy Brief. Sustainable Development in Bangladesh: Facing Global Environmental Change. South Asian Disaster Management Center. IUBAT University, Dhaka, Bangladesh. 2015.

14. Khan MA, Shamsuddoha M, Addulla A Helal, Hassan A. Climate Change Mitigation Approaches in Bangladesh. J of Sus Dev. 2013:6(7).

15.ibid

16.ibid

17.ibid

18. Bhowmik NC. Bangladesh: renewable Energy report, Asian and pacific center for transfer of Technology of the United Nations-Economic and Social Commission for Asia and the Pacific. 2008.

19. Bahauddin KM, Saluddin TM. Prospect and Trend of Renewable Energy and Its Technology towards Climate Change Mitigation and Sustainable development in Bangladesh. International Journal of Advanced renewable Energy Research. 2012:156-166.

20.SADMC. Policy Brief. Sustainable Development in Bangladesh: Facing Global Environmental Change. South Asian Disaster Management Center. IUBAT University, Dhaka, Bangladesh. 2015.

21. Robert Watkins. UN Resident Coordinator in Bangladesh. The Daily Star. 2015.

22. Tim Cadman. Paper presented in an International Seminar on Understanding the Climate Regime Post Paris: COP 21 Update. SADMC, IUBAT University. 2016

23. Hugh Breakey. Research Fellow. Political Philosophy. Grifith University, Australia (Commentator)

24. Ibid

25. WCED. Our Common Future. World Commission on Environment and Development, Oxford University Press. 1987.

26. Lafferty W. Governance for Sustainable Development: the Challenge of Adapting Form to Function. 2004.

27. Gibson R, Hassan S, Holtz S, Tansey J, Whitelaw G. Sustainability Assessment, Earthscan. Gill G. the Nature and Development of the Modern State, Palgrave. 2005.

28. Timothy Cadman. Quality and Legitimacy of Global Governance. Case Lessons from Forestry. Palgrave Macmillan. 2011.

29. Ibid

30. CCG. The climate change governance ICCCAD. 2013.

31. Ibid

32. Nicholas Genis. Keynote Paper: Education for Sustainable Development. International Faculty ,Centre for Global Environmental Culture (CGEC), IUBAT

33. World Bank Report. Policy Research Working Paper 4941. Climate Change Governance by James Meadowcroft. 2009. 